ORIGINAL ARTICLE

\title{
Asymptomatic Plasmodium falciparum infection and poor school performance in primary school children in the Volta Region of Ghana
}

\author{
Orish Verner ${ }^{*}$, Amegan Aho Kokou ${ }^{2}$, Ofori-Amoah Jones ${ }^{3}$, Osei-Yobah \\ James $^{4}$, Jamfaru Ibrahim ${ }^{1}$, Afeke Innocent ${ }^{4}$, Mac-Ankrah Lennox ${ }^{1}$, Adzaku \\ Festus $^{5}$
}

OPEN ACCESS

Citation: Orish Verner, Amegan Aho Kokou, Ofori-Amoah Jones, et al. Asymptomatic Plasmodium falciparum infection and poor school performance in primary school children in the Volta Region of Ghana. Ethiop J Sci. 2018; 28(6):749.

doi:http:// dx.doi.org /10.4314/ejhs.v28i6.10

Received: February 25, 2018

Accepted: April 5, 2018

Published: April 20, 2018

Copyright: (C) 2018 Orish V., et al. This is an open access article distributed under the terms of the Creative Commons Attribution License, which permits unrestricted use, distribution, and reproduction in any medium, provided the original author and source are credited.

Funding: Nil

Competing Interests: The authors declare that this manuscript was approved by all authors in its form and that no competing interest exists.

Affiliation and Correspondence:

${ }^{1}$ Department of Microbiology and Immunology, School of Medicine, University of Health and Allied Sciences, Ho Volta Region, Ghana, West Africa

${ }^{2}$ Department of Paediatrics, Schoolof Medicine, University of Health and Allied Sciences, Ho, Ghana

${ }^{3}$ Department of Pharmacology, School of Medicine, University of Health and Allied Sciences, Ho, Volta Region, Ghana

${ }^{4}$ Department of Medical Laboratory Sciences, School of Allied Health Sciences, University of Health and Allied Sciences, Ho, Ghanaa

${ }^{5}$ School of Basic and Biomedical Sciences, University of Health and Allied Sciences, Ho, Ghanaa

*Email: orishv@yahoo.com

\section{ABSTRACT}

BACKGROUND: This study aimed to evaluate the association between asymptomatic Plasmodium falciparum infection and poor intellectual development in primary school children in the Volta Region of Ghana.

METHODS: This was a cross-sectional study conducted among children from 5 primary schools in 3 districts in the Volta region of Ghana. Questionnaires were administered, and blood samples collected for malaria investigation using Rapid diagnostic test (RDT) and microscopy. School performance was used to assess intellectual development in the children. Arithmetic was the subject of choice for the standardized test. Pearson chi square test was used to evaluate the association between Plasmodium falciparum and poor school performance. Multivariate analysis was used to identify factors independently associated with risk of poor school performance.

RESULTS: Out of 550 children, 305(55.45\%) tested positive for malaria with RDT and 249(45.27\%) positive with microscopy. Children from the Evangelical Presbyterian (EP) primary school in Afegame had the highest prevalence of Plasmodium falciparum infection with both $R D T$ (92, 74.80\%) and microscopy (73, 59.35\%). Two hundred and fifteen students (39.09\%) failed the arithmetic school test. EP primary school in Afegame recorded the highest frequency of poor school performance among the children (53.66\%). School performance was significantly associated with RDT malaria diagnosis with failure rate higher among children who were $R D T$ positive $(135,62.79 \%, p=0.005)$. Lower mean scores were seen in children with positive RDT result $(47.35$, [SD 30.85], $p=0.021$ ). Plasmodium falciparum infection (RDT) was independently associated with increased risk of poor school performance (AOR, 1.92, $p=0.003$ ).

CONCLUSION: An urgent scale-up of malaria control program targeting school-going children in this region is needed to mitigate the possible negative impact of Plasmodium falciparum infection on their intellectual development. 


\section{INTRODUCTION}

Malaria poses a great threat to the wellbeing of children living in endemic areas $(1,2)$. Aside contributing a great deal to mortality in children, it also contributes immensely in impacting negatively on the physical and intellectual development of children (3-6). Existing research works indicate that infections from Plasmodium falciparum, which is the deadliest and the most predominant species of Plasmodium, causes severe malaria and repeated uncomplicated malaria in many countries; and have also been implicated for the depreciating poor intellectual development in children (7-11). However, few studies have linked asymptomatic $\boldsymbol{P}$. falciparum infection to poor intellectual development in children in sub-Saharan Africa (12).

Many studies have employed school performance as a proxy for intellectual development, using standardized school test in arithmetic and local language $(13,7,8,9)$. Other tools like Denver Developmental Screening Test and Ravens Matrices that also assess mental and intellectual development of children have also been used in fewer studies $(14,12)$.

Despite gains in malaria control in Ghana, malaria infections still pose a serious threat to children in the country, especially those living in rural areas (15). Ghana has a vibrant school health program, which involves school feeding program and periodic deworming exercise targeting intestinal helminths and Schistosoma infections in school aged children (16). However, in terms of malaria control, neither the school health program nor the national malaria control program targets school-going children. Very little information can be found on the evaluation of the impact of malaria on the intellectual development of schoolaged children in Ghana. This study, therefore, sought to determinethe the association between asymptomatic $\boldsymbol{P}$. falciparum infection and poor intellectual development in primary school children in the Volta Region of Ghana.

\section{METHODS}

Study area: This study was carried out in two districts and one municipality of the Volta Region of Ghana. The Volta Region is one of the ten regions in Ghana located between latitudes 50 $45^{\mathrm{ee}} \mathrm{N}$ and $8045^{\mathrm{ee}} \mathrm{N}$ in the south eastern part of the country, bounded by Togo on the east and Lake Volta on the west. The study area included Ho municipal area (regionaladministrative capital), as well as Adaklu, and Agotime-Ziope districts. Adaklu is predominantly a rural district; while Agotime-Ziope has about $25 \%$ of its population living in the capital of the district which is urban. Ho municipality on the other hand is predominantly an urban area, with about $30 \%$ of the population living in rural areas.

Study design and procedure: This was a crosssectional study involving administration of questionnaires and standardized school test, as well as blood sample collection. These activities took place from March $14^{\text {th }}$ to April $14^{\text {th }} 2016$, between 9:30am and 3pm each day.

School children from the ages of 6 to 14 years were selected from primary schools in the three districts. Primary schools, in both urban and rural settings, were particularly selected for this study (17). A total of five primary schools were selected for this study; namely, Freetown Pimary Shool in the Ho municipality, Dave and Davanu Primary schools in Adaklu district and the Evangelical Presbyterian[EP] Primary schools in Afegame and Kpetoe, both in Agotime-Ziope district.

Sample size calculation: A recommended minimum sample size of 335 was generated using the Cochran formula at $95 \%$ confidence interval, 5\% margin of error. A prevalence rate of $67.8 \%$ was used, being the prevalence of malaria among school children in Adaklu and AgotimeZiopedistrict in Volta region (18).

Ethical clearance: Ethical clearance was obtained from the Ghana Health Service Ethical Committee [ID NO:GHS-ERC: 29/11/15). Written informed consent was gotten from the parents of children who participated in the study. Assent 
forms were signed by the children before they were enrolled onto the study.

Data/sample collection: Data and sample collections were performed using methods and procedure as previously described by Orish et al. (17). Briefly, questionnaires were administered to children recruited for this study to obtain information about their demographic and socioeconomic status, vis-á-vis: occupation of both parents, the type of housing they live in, family size, as well as the identity of the guardian they stay with, and if they have been using mosquito net. Blood samples were also collected from each participant by a trained phlebotomist and transferred into ethylenediaminetetraacetic acid (EDTA) anticoagulant tubes. These samples were transported in an ice chest to the laboratory on the same day, and malaria investigation then conducted using Rapid Diagnostic Test (RDT) and microscopy. Bioline SD kit from Standard Diagnostics, INC., South Korea, was used in the detection of histidine rich protein 2 (HRP-2) of $\boldsymbol{P}$. falciparum. All the procedure and tests followed strict observance of the manufacturer's instructions. Microscopy involved 10\% Geimsa preparation of thin and thick film on a slide; and the slides were read by two and/or three microscopists where there were discordant results. The presence of asexual forms of the parasite in the blood smear was considered positive. Haemoglobin estimation was also performed using haematology analyzer (Sysmex, Kakogawa, Japan).

Definitions: Asymptomatic $\boldsymbol{P}$. falciparum infection was defined as positive RDT, or microscopy results with no associated clinical symptoms. Anaemia was classified as severe $(\mathrm{Hb}<7 \mathrm{~g} / \mathrm{dl})$, moderate [7-9.9g/dl], and mild $[<11 \mathrm{~g} / \mathrm{dl}](19)$.

Assessment of school performance: School performance assessment was done using standardized school test. Arithmetic was chosen as the subject for assessment. Questions were gotten from the office of the Volta Region directorate of education. The test was administered to each pupil from the five primary schools, based on their level in school. Ten questions were set for each level, and tests were administered in standard examination setting and condition for 20 minutes. Results of the tests were marked and graded over $100 \%$ by a trained educationist from the Ghana Education Service. Pass mark was fixed at $50 \%$ and above, while failure was below $50 \%$.

Statistical analyses: A frequency distribution was performed for characteristics like malaria, anaemia and poor school performance. Pearson $\chi^{2}$ tests analysis was used to investigate the association between poor school performanceand $\boldsymbol{P}$. falciparum infection, as well as anaemia and socioeconomic status. Multivariate logistic regression was used to identify factors independently associated with the risk of poor school performance in the primary school children. Analyses were done with 95\% confidence interval $(\mathrm{CI})$ and a $\mathrm{p}$ value of 0.05 or below (i.e. $p \leq 0.05$ ) was considered statistically significant. All statistical analyses were performed using IBM SPSS Statistical softwares version 21.0 (IBM Corporation, Armonk, NY, USA).

\section{RESULTS}

A total of 550 primary school children were recruited for this study. Figure 1 gives the overview of the study population. It shows thenumber of children enrolled for each school, available participants and children who successfully participated by answering the questions from the questionnaire taking the standardize test as well as having blood samples collected from them. 


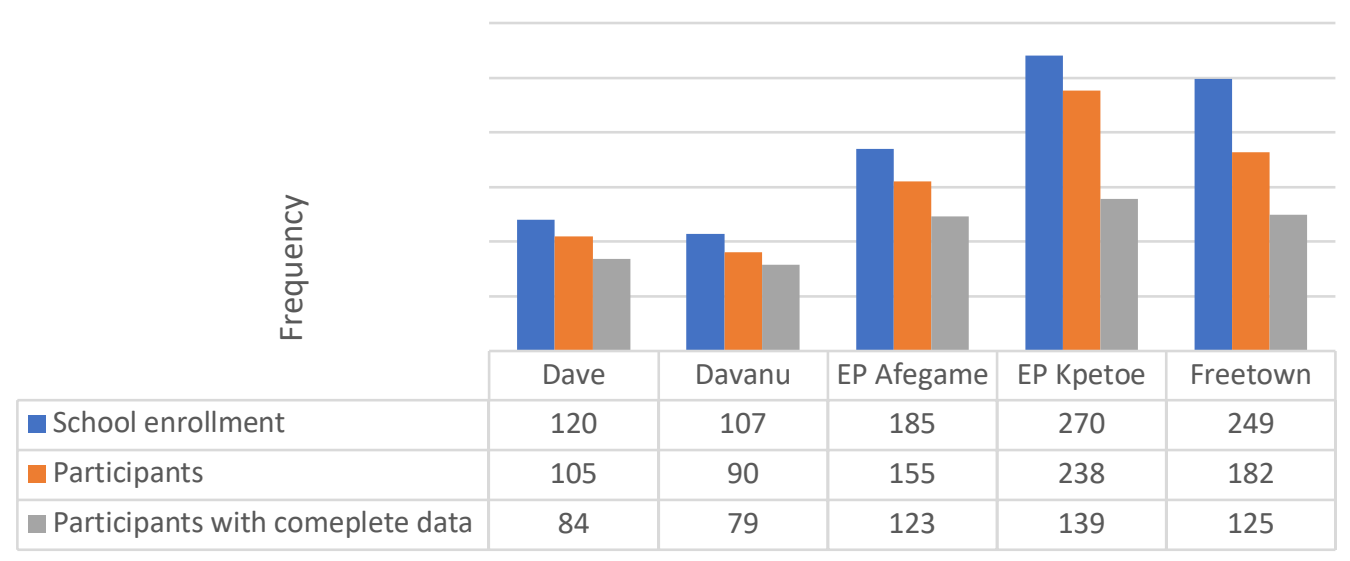

Figure 1: Overview of study population in the 5 primary schools

Table 1 shows the prevalence of $P$. falciparuminfection among the primary school children. Rapid diagnostic test (RDT) was positive for $55.45 \%(305 / 550)$ of the children while $45.27 \%(249 / 550)$ was with microscopy. There was a significant difference in the prevalence of $P$. falciparum infection among the children in the 5 primary schools (RDT, $\mathrm{p}<0.001$; Microscopy, $p=0.007)$. Children from EP Afegame school had the highest prevalence of $P$. falciparum for RDT (92, 74.80\%)) and microscopy $(73,59.35 \%)$.

Table 2 highlights the characteristics of the primary school children in the studybased on their school performance in the arithmetic test. Two hundred and fifteen students (39.09\%) failed the arithmetic school test. There were no significant association seen between poor school performance and occupation of parents, house type, family size, who child stays with, and sex. However, there was significant association seen with $P$. falciparum infection and anaemia, with higher proportion of children who failed the arithmetic school test being positive with RDT $(135,62.79 ; \mathrm{p}=0.001)$ and anaemic $(48,47.52 \%$; $\mathrm{p}=0.03)$.

Table 1: Prevalence of P. Falciparum infection among children in five primary schools in Volta Region

\begin{tabular}{lccc}
\hline Parameter & Malaria Positive & Malaria Negative & P value \\
\hline Rapid Diagnostic Test & $\mathbf{3 0 5}(\mathbf{5 5 . 4 5})$ & $\mathbf{2 4 5 ( 4 4 . 5 5 )}$ & \\
Freetown (Ho municipality) & $60(48.00)$ & $65(52.00)$ & $<0.001$ \\
Davanu (Adaklu district) & $57(72.15)$ & $22(27.85)$ & \\
Afegame (Agotimeziope district) & $92(74.80)$ & $31(25.20)$ & \\
Kpetoe (Agotimeziope district) & $58(41.73)$ & $81(58.27)$ & \\
Dave (Adaklu district) & $38(45.24)$ & $46(54.76)$ & \\
Microscopy & $\mathbf{2 4 9 ( 4 5 . 2 7 )}$ & $\mathbf{3 0 1 ( 5 4 . 7 3 )}$ & \\
\hline Freetown (Ho municipality) & $48(38.40)$ & $77(61.60)$ & 0.007 \\
Davanu (Adaklu district) & $36(45.57)$ & $43(54.43)$ & \\
Afegame (Agotimeziope district) & $73(59.35)$ & $50(40.65)$ & \\
Kpetoe (Agotimeziope district) & $54(38.85)$ & $85(61.15)$ & \\
Dave (Adaklu district) & $38(45.24)$ & $46(54.76)$ & \\
\hline Da
\end{tabular}

Data is presented as frequency with corresponding percentage in parenthesis. $\mathrm{p}$ is significant at $\mathbf{0 . 0 5}$.

DOI: http://dx.doi.org/10.4314/ejhs.v28i6.10 
Table 2: Characteristics of Children according to performance in the arithmetic school test.

\begin{tabular}{|c|c|c|c|}
\hline Characteristics & Fail $=215$ & Pass $=335$ & p value \\
\hline \multicolumn{4}{|l|}{ Gender } \\
\hline Male & 99(39.76) & $150(60.24)$ & 0.43 \\
\hline Female & $116(38.54)$ & $185(61.46)$ & \\
\hline \multicolumn{4}{|c|}{ Occupation of mother } \\
\hline Trader & $128(38.32)$ & $206(61.68)$ & 0.64 \\
\hline Farmer & $65(41.67)$ & $91(58.33)$ & \\
\hline Civil servant & $11(32.35)$ & $23(67.65)$ & \\
\hline Unemployed & $11(42.31)$ & $15(57.69)$ & \\
\hline \multicolumn{4}{|c|}{ Occupation of father } \\
\hline Trader & 97(38.19) & $157(61.81)$ & 0.97 \\
\hline Farmer & $67(39.41)$ & $103(60.59)$ & \\
\hline Civil servant & $41(39.81)$ & $62(60.19)$ & \\
\hline Unemployed & $10(43.48)$ & $13(56.52)$ & \\
\hline \multicolumn{4}{|l|}{ House types } \\
\hline Family house & $77(39.29)$ & $119(60.71)$ & 0.52 \\
\hline Single room & $65(39.39)$ & $100(60.61)$ & \\
\hline Semi detached & $73(38.62)$ & $116(61.38)$ & \\
\hline \multicolumn{4}{|l|}{ Family size } \\
\hline 2 & $28(40.58)$ & $41(59.42)$ & 0.5 \\
\hline 3 & $54(45.00)$ & $66(55.00)$ & \\
\hline 4 & $38(14.15)$ & $68(64.15)$ & \\
\hline 5 & $35(36.46)$ & $61(63.54)$ & \\
\hline 6 & $22(33.85)$ & $43(66.15)$ & \\
\hline$>6$ & $38(40.43)$ & $56(59.57)$ & \\
\hline \multicolumn{4}{|c|}{ Who child stays with } \\
\hline Father & $12(48.00)$ & $13(52.00)$ & 0.48 \\
\hline Mother & $31(38.75)$ & $49(61.25)$ & \\
\hline Both parents & $121(38.05)$ & 197(61.95) & \\
\hline Grand parents & $31(44.29)$ & $39(55.71)$ & \\
\hline Others & $20(35.09)$ & $37(64.91)$ & \\
\hline \multicolumn{4}{|c|}{ P. falciparum infection } \\
\hline $\mathrm{RDT}+\mathrm{ve}$ & $135(62.79)$ & $170(50.75)$ & 0.001 \\
\hline RDT-ve & $80(37.21)$ & $165(49.25)$ & \\
\hline $\mathrm{MP}+\mathrm{ve}$ & $103(47.91)$ & $146(43.58)$ & 0.21 \\
\hline MP-ve & $112(52.09)$ & $189(56.42)$ & \\
\hline \multicolumn{4}{|l|}{ Haemoglobin } \\
\hline$<11 \mathrm{~g} / \mathrm{dl}$ & $48(47.52)$ & $53(52.48)$ & 0.03 \\
\hline$\geq 11 \mathrm{~g} / \mathrm{dl}$ & 167(37.19) & $282(62.81)$ & \\
\hline \multicolumn{4}{|l|}{ Name of school } \\
\hline Dave & $34(17.86)$ & $50(82.14)$ & $<0.001$ \\
\hline Freetown & $32(25.60)$ & $93(74.40)$ & \\
\hline Davanu & $32(40.51)$ & $47(59.49)$ & \\
\hline Afegame & $66(53.66)$ & $57(46.34)$ & \\
\hline Kpetoe & $51(36.69)$ & $88(63.31)$ & \\
\hline
\end{tabular}

DOI: http://dx.doi.org/10.4314/ejhs.v28i6.10 
There was also a significant difference in the prevalence of poor school performance of the children amongthe five schools $(p<0.001)$, with the EP primary school in Afegame having the highest prevalence of poor school performance in the arithmetic school test $(53.66 \%)$.

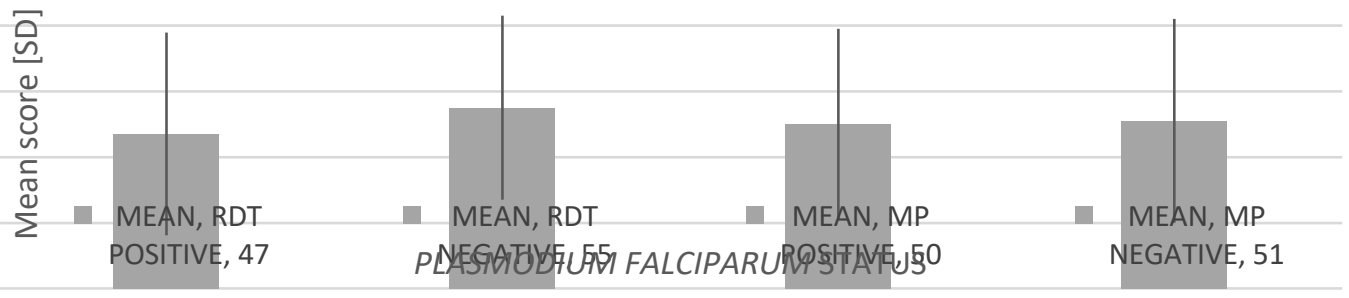

Fig. 2. Mean score and standard deviation of the standardized arithmetic test for children positive and negative for both RDT and microscopy.

Figure 2 shows the mean score and standard deviation of the standardize arithmetic test for children positive and negative for both RDT and microscopy. Children positive with RDT significantly had the lowest mean score (47[SD30.85], $\mathrm{p}=0.021$ ). Those positive with microscopy had a lower mean score (50 [SD 29]) compared to those negative with microscopy (51[SD $31]$ ), but this finding was not significant $(\mathrm{p}=0.92)$.

Table 3 summarizes the factors that predicted the risk of poor school performance in arithmetic among the primary school children in this study. Children attending EP primary school in Afegame had the highest risk of having a poor school performance with unadjusted OR of $2.86(95 \% \mathrm{CI}$, $1.57-5.20 ; \mathrm{p}=0.001)$ and adjusted OR of $2.67(95 \%$ CI, 1.44-4.96; $\mathrm{p}=0.002$ ). P. falciparum (RDT) was independently associated with increased risk of poor school performance. Children with $P$. falciparum positive (RDT) had higher risk of poor school performance (Unadjusted OR, 2.01; 95\%, CI, 1.333.06; $\mathrm{p}=0.001$ : Adjusted OR, 1.92, 95\% CI, 1.252.94; $\mathrm{p}=0.003)$. Children with haemoglobin level less than $11 \mathrm{~g} / \mathrm{dl}$ were more likely to have poor school performance (Unadjusted OR, 1.76; $\mathrm{p}=0.04$ ). However, significance was lost $(\mathrm{p}=0.13)$ after controlling for confounders like $P$. falciparumand the primary school attendance.

Table 3: Multivariate logistics regression analysis of poor school performance risk among the primary school children .

\begin{tabular}{|c|c|c|c|c|}
\hline Variable & Unadjusted OR(95\% CI) & p value & Adjusted OR(95\% CI) & p value \\
\hline \multicolumn{5}{|l|}{ Gender } \\
\hline Male & $1.05(0.70-1.58)$ & 0.78 & $1.02(0.67-1.53)$ & 0.95 \\
\hline Female & Ref & & & \\
\hline \multicolumn{5}{|l|}{ School } \\
\hline Dave Prim. & $1.16(0.57-238)$ & 0.69 & $1.11(0.52-2.36)$ & 0.79 \\
\hline Freetown Prim. & $0.70(0.38-1.27)$ & 0.24 & $0.67(0.36-1.22)$ & 0.19 \\
\hline Davanu Prim. & $1.42(0.74-2.75)$ & 0.3 & $1.39(0.70-2.76)$ & 0.35 \\
\hline Afegame EP & $2.86(1.57-5.20)$ & 0.001 & $2.67(1.44-4.96)$ & 0.002 \\
\hline Kpetoe EP & Ref & & & \\
\hline \multicolumn{5}{|l|}{ Malaria (RDT) } \\
\hline Positive & $2.01(1.33-3.06)$ & 0.001 & $1.92(1.25-2.94)$ & 0.03 \\
\hline Negative & Ref & & & \\
\hline \multicolumn{5}{|l|}{ Hemoglobin } \\
\hline$<11 \mathrm{~g} / \mathrm{dl}$ & $1.76(1.02-3.04)$ & 0.04 & $1.56(0.86-2.78)$ & 0.13 \\
\hline$\geq 11 \mathrm{~g} / \mathrm{dl}$ & Ref & & & \\
\hline
\end{tabular}

DOI: http://dx.doi.org/10.4314/ejhs.v28i6.10 


\section{DISCUSSION}

To the best of our knowledge, this is the first workthat has attempted to assess the association between $P$. falciparuminfection and intellectual development in children in Ghana.

There was a high prevalence of $P$. falciparumof $45.3 \%$ and $55.5 \%$ with microscopy and RDT respectively, which is not uncommon within the region and other parts of Ghana (17, 20); although another study reported a much lower prevalence in the region(21). The $P$. falciparum infections in this study were mainly asymptomatic, which is the predominant presentation of infections in malaria endemic environment (22).It is known that older children, especially school-going children are usually asymptomatic with $P$. falciparuminfection (23). There was a difference between RDT positive and microscopy positive $P$. falciparum infection in this study. This discrepancyhas been widely reported by several other studies (24-26). The strength and weakness of these two malaria diagnostic methods may be responsible for the differences in results(24).Microscopy is regarded as the gold standard, but its availability and high expertise required makes it unsuitable in certain instances $(24,26)$. For RDT, it requires very little expertise and results are promptly available(24). The downside however for RDT is that it requires a higher parasite threshold $(\geq 200 \mathrm{p} / \mu \mathrm{l})$ to generate adequate titreof antigens to be detected $(24,27)$. Despite thisfactor, most RDTs have over $95 \%$ sensitivity especially those specific for $P$. falciparumwhichwas used in this study $(28,29)$. More so, in some studies, RDT has demonstrated to be more accurate and sensitive compared to microscopy, using Polymerase chain reaction (PCR) as standard $(26,30)$.

Poor school performance was significantly associated with $P$. falciparum infected children (RDT). This finding was supported by the result showing children from the Evangelical Presbyterian (EP)Primary school in Afegame having the highest poor school performance, since this particular school significantly $(\mathrm{p}<0.001)$ had the highest prevalence of $P$. falciparuminfection. $P$. falciparum and
Afegame EP primary school were independently associated with increased risk of poor school performance in the children. These findings are in agreementwith otherstudiesthat reported malaria causing poor scores in arithmetic among children who are infected $(7,8)$. These studies argued that these poor results in the standardized school test is due to the impairment of the intellectual development of the infected children by malaria $(7,8,9)$. The mechanisms behind this impairment have been linked to severe, repeated, uncomplicated and asymptomatic malaria $(7,8,9$, 12).It is believed that the cytokines released during malaria infection play a role in depreciating cognitive function in children who recover $(7,31)$. In the case of asymptomaticand uncomplicated malaria, repeated infection and their adverse impact on cognition have been implicated $(4,7,12)$.

Anaemia is another proposed pathway of cognitive impairment from malaria infection (32, 33).Repeated asymptomatic malaria can cause chronic iron deficiencyanaemia which has an adverse impact on cognition $(34,35)$. However, in this study anaemia was not independently associated with increased risk of poor school performance in arithmetic standardized test; probably suggesting that the impairment here might be due to a more direct immunologic pathway $(12,31)$.

There was no significant association seen with socioeconomic factorssuch as parents'occupation, house type, who child stays with, and poor school performance in this study. Some studies reported association between socioeconomic factors and poor school performance and cognitive function $(7,12)$. Other factors which can impairintellectual development in children and cause poor school performance like helminths infections were not mentioned in this study. However, the reported low levels of intestinal helminths infections among primary school children in this region $(21,36)$, and the periodic deworming exercise targeting intestinal helminths and Schistosomainfections(16,21), make it less likely for helminths infections to contribute significantly to impaired intellectual 
development and poor school performance in this study.

This was a cross-sectional study which cannot state in categorical terms the causality between asymptomatic infections and poor school performance. However, reverse causality is very much unlikely to happen between asymptomatic malaria and poor school performance; since poor school performance cannot cause malaria infection(12). Furthermore, this study cannot completely ascertain if the association noted was the lingering effect of previous symptomatic malaria attack on the children or the current asymptomatic status. However,efforts were made to control for other confounders that might have impacted poor school performance in the primary school children, like socioeconomic factors (parent's occupation, family size and parental care) in this study.

Our study reported a significant association between asymptomatic P.falciparum malariaand poor school performance in arithmetic standardized school test. Also, children in Afegame, with the highest prevalence of $P$. falciparum infection had the poorest performance in the school test. More studies areneeded to throw more light on this association between malaria and intellectual development inschool children in Ghana. This will ensure the consolidation of the gains of malaria control and the school health programs.

\section{REFERENCES}

1. Keiser J, Utzinger J, De Castro MC, Smith TA, Tanner M, Singer BH. Urbanization in sub-saharan Africa and implication for malaria control. The American journal of tropical medicine and hygiene, 2004;71(2_suppl):118-27.

2. Bull PC, Marsh K. The role of antibodies to Plasmodium falciparum-infected-erythrocyte surface antigens in naturally acquired immunity to malaria. Trends in Microbiol, 2002;10:55-8.

3. Sharp PT \& Harvey P. Malaria and growth stunting in young children of the highlands of Papua New Guinea. Papua and New Guinea medical journal, 1980; 23(3):132-140.
4. Holding PA \& Snow RW. Impact of Plasmodium falciparum malaria on performance and learning: review of the evidence. The American journal of tropical medicine and hygiene, 2001; 64(1 suppl):6875.

5. Takakura M, Uza M, Sasaki Y, et al. The relationship between anthropometric indicators of nutritional status and malaria infection among youths in Khammouane Province, Lao PDR. The southeast Asian Journal of Tropical Medicine and Public health, 2001; 32(2):262-267.

6. Holding PA \& Kitsao-Wekulo PK. Describing the burden of Malaria on child development: What should we be measuring and how should we be measuring it?.The American journal of tropical medicine and hygiene, 2004; 71(2 suppl): 71-79.

7. Fernando SD, Gunawardena DM, Bandara MRSS, et al. The impact of repeated malaria attacks on the school performance of children. The American journal of tropical medicine and hygiene, 2003; 69(6): 582-588.

8. Vitor-Silva S, Reyes-Lecca RC, Pinheiro TR \& Lacerda MV. Malaria is associated with poor school performance in an endemic area of the Brazilian Amazon. Malaria Journal, 2009; 8(1):230.

9. Vorasan N, Pan-Ngum W, Jittamala P, Maneeboonyang W, Rukmanee P \& Lawpoolsri S. Long-term impact of childhood malaria infection on school performance among school children in a malaria endemic area along the Thai-Myanmar border. Malaria journal, 2015;14(1):401.

10. Mendis K \& Nabarro D. Roll back malaria unarguably necessary and possible. Bull world health organ, 2001; 78(12):1454-5.

11. Rowe JA, Claessens A, Corrigan RA \& Arman M. Adhesion of Plasmodium falciparum-infected erythrocytes to human cells: molecular mechanisms and therapeutic implications. Expert reviews in molecular medicine, 2009; 11:e16.

12. Nankabirwa J, Wandera B, Kiwanuka N, Staedke SG, Kamya MR, \& Brooker SJ. Asymptomatic Plasmodium infection and 
cognition among primary schoolchildren in a high malaria transmission setting in Uganda. The American journal of tropical medicine and hygiene, 2013; 88(6):1102-1108.

13. Nokes C, Cooper ES, Robinson BA \& Bundy DA. Geohelminth infection and academic assessment in Jamaican children. Transactions of the Royal Society of Tropical Medicine and Hygiene, 1991; 85(2): 272-273.

14. Oberhelman RA, Guerrero ES, Fernandez $\mathrm{ML}$, et al. Correlations between intestinal parasitosis, physical growth, and psychomotor development among infants and children from rural Nicaragua. The American journal of tropical medicine and hygiene, 1998; 58(4):470-475.

15. Orish VN, Ansong JY, Anagi IB, et al. Malaria and associated co-morbidity in children admitted with fever manifestation in Western Ghana: A retrospective study. The Journal of Infection in Developing Countries, 2015; 9(11):1257-1263

16. Abdul-Rahman L, and Agble R. Review of school health and nutrition interventions and mapping existing programmes in Ghana. London UK partnership for child development, 2012.

17. Orish, VN, Amegan-Aho KH, Ofori-Amoah, $\mathrm{J}$, et al. High Prevalence of AsymptomaticPlasmodium falciparum Infections in Primary School Children in the Volta Region of Ghana. Texila International Journal of Public Health, 2017; 5 (3):4.

18. Egbi, G., Steiner-Asiedu, M., Kwesi, FS., Ayi, I., Ofosu, W., Setorglo, J., \&ArmarKlemesu, M. Anaemia among school children older than five years in the Volta Region of Ghana. Pan African Medical Journal, 2014; 17(Suppl 1).

19. World Health Organization. Worldwide prevalence of anaemia 1993-2005. 2008; 140.

20. Sarpong N, Owusu-Dabo E, Kreuels B, et al. Prevalence of malaria parasitaemia in school children from two districts of Ghana earmarked for indoor residual spraying: a cross-sectional study. Malaria journal, 2015; 14(1):260.
21. Ayeh-Kumi PF, Addo-Osafo K, Attah SK, et al. Malaria, helminths and malnutrition: a cross-sectional survey of school children in the South-Tongu district of Ghana. BMC research notes, 2016; 9(1):242.

22. Lindblade KA, Steinhardt L, Samuels A, Kachur SP \& Slutsker L. The silent threat: asymptomatic parasitemia and malaria transmission. Expert review of anti-infective therapy, 2013; 11(6):623-639.

23. Walldorf JA, Cohee LM, Coalson JE, et al. School-age children are a reservoir of malaria infection in Malawi. PLoS One, 2015; 10(7): e0134061.

24. Wongsrichanalai C, Barcus MJ, Muth S, Sutamihardja A \& Wernsdorfer, WH. A review of malaria diagnostic tools: microscopy and rapid diagnostic test (RDT). The American journal of tropical medicine and hygiene, 2007; 77(6 Suppl): 119-127.

25. Keating J, Miller JM, Bennett A, Moonga H $\&$ Eisele TP. Plasmodium falciparum parasite infection prevalence from a household survey in Zambia using microscopy and a rapid diagnostic test: implications for monitoring and evaluation. Acta tropica, 2009;112(3):277-282

26. Golassa L, Enweji N, Erko B, Aseffa A, \& Swedberg G. Detection of a substantial number of sub-microscopic Plasmodium falciparum infections by polymerase chain reaction: a potential threat to malaria control and diagnosis in Ethiopia. Malaria journal, 2013;12(1):352.

27. Hopkins H, Kambale W, Kamya MR, et al. Comparison of HRP2-and pLDH-based rapid diagnostic tests for malaria with longitudinal follow-up in Kampala, Uganda. The American journal of tropical medicine and hygiene, 2007;76(6):1092-1097.

28. World Health Organization. New perspectives: malaria diagnosis. Report of a Joint WHO/USAID Informal Consultation, 25-27 October 1999. New perspectives: malaria diagnosis 2000. Report of a Joint WHO/USAID Informal Consultation, 25-27 October 1999. 
29. Forney JR, Wongsrichanalai C, Magill A. et al. Devices for rapid diagnosis of malaria: evaluation of prototype assays that detect Plasmodium falciparum histidine-rich protein 2 and a Plasmodium vivax-specific antigen. Journal of clinical microbiology, 2003;41(6): 2358-2366.

30. Batwala, V., Magnussen, P., \&Nuwaha, F. Are rapid diagnostic tests more accurate in diagnosis of plasmodium falciparum malaria compared to microscopy at rural health centres?. Malaria journal, 2010; 9(1):349.

31. John CC, Panoskaltsis-Mortari A, Opoka R. et al. Cerebrospinal fluid cytokine levels and cognitive impairment in cerebral malaria. The American journal of tropical medicine and hygiene, 2008; 78(2):198-205.

32. Kurtzhals, JA, Addae MM, Akanmori BD, et al. Anaemia caused by asymptomatic Plasmodium falciparum infection in semiimmune African schoolchildren. Transactions of the Royal Society of Tropical Medicine and Hygiene, 1999; 93(6):623-627.

33. Agaoglu L, Torun O, Unuvar E, Sefil Y, \& Demir D. Effects of iron deficiency anaemia on cognitive function in children. Arzneimittelforschung 2007; 57(06):426-430.

34. Halterman JS, Kaczorowski JM, Aligne CA, Auinger P \& Szilagyi PG. Iron deficiency and cognitive achievement among schoolaged children and adolescents in the United States. Pediatrics, 2001;107(6):1381-1386.

35. Grantham-McGregor S, \& Ani C. A review of studies on the effect of iron deficiency on cognitive development in children. The Journal of nutrition, 2001; 131(2):649S-668S.

36. Orish VN, Ofori-Amoah J, Amegan-Aho KH, et al. Low Prevalence of Helminth Infectionsamong Primary School Children in the Volta Region of Ghana. Asian Journal of Medicine and Health, 2017;5(3):1-9.

DOI: http://dx.doi.org/10.4314/ejhs.v28i6.10 